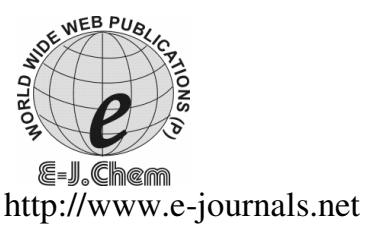

\title{
Cobalt and Nickel Complexes Bearing 2,6-Bis(imino)phenoxy Ligands: Synthesis and Ethylene Oligomerization Study
}

\author{
JIAN-LONG DU* and LI-JUN LI \\ College of Chemistry and Environmental Science \\ Hebei University, Baoding 071002, P.R. China
}

Received 4 April 2006; Accepted 23 June 2006

\begin{abstract}
A series of new cobalt and nickel complexes $\mathrm{MLX}_{2}(\mathrm{M}=\mathrm{Co}$ or $\mathrm{Ni}, \mathrm{X}=$ $\mathrm{Cl}$ ) bearing 2,6-bis(imino)phenoxy ligands have been synthesized. Treatment of the complexes with methylaluminoxane (MAO) leads to active catalysts for ethylene oligomerization. The oligomers are olefins from $\mathrm{C}_{4}$ to $\mathrm{C}_{6}$.
\end{abstract}

Keywords: Nickel, cobalt, 2,6-bis(imino)phenoxy, ethylene oligomerization

\section{Introduction}

Late-transition metal complex as catalyst for olefin polymerization and oligomerization is an intense subject of academic research and industrial application. ${ }^{1-2}$ Recent progress was employing cationic $\mathrm{Ni}(\mathrm{II})$ bis(imino) complexes as effective catalysts for ethylene oligomerization and polymerization. ${ }^{3-5}$ Brookhart, Bennett and Gibson had made great contribution to design highly active ethylene polymerization catalysts based on iron (II) and cobalt (II) bearing 2,6-bis(imino)pyridyl ligands.$^{6-8}$ Moreover, Grubbs reported new neutral $\mathrm{Ni}$ (II) salicylaldimiminato complexes as catalysts for the polymerization of ethylene to obtain high molecular weight polyolefin under moderate conditions. ${ }^{9}$ Modification of the 
substituents of imino groups results in dramatic changes to the resultant polyolefin. ${ }^{10}$ Sun also reported a series of salicylaldimiminato complexes as catalysts for the polymerization of ethylene. ${ }^{11}$ Now we focus on exploring the effect of changing the central pyridyl moiety to phenol. Herein, we report the synthesis of $\mathrm{Co}(\mathrm{II})$ and $\mathrm{Ni}(\mathrm{II})$ complexes bearing 2,6bis(imino)phenoxy ligands and their ethylene oligomerization activity.

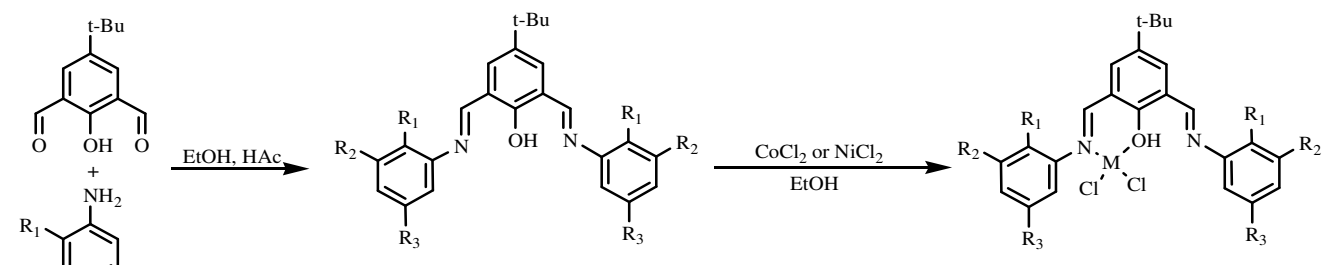

Scheme 1. Synthetic procedure for the catalysts

\section{Experimental}

All manipulations were carried out under an atmosphere of nitrogen using standard Schlenk and Cannula techniques. Using HP-MOD 1106 microanalyzer performed elemental analysis. NMR spectra were recorded on a Bruker spectrometer DMX-300, with TMS as the internal standard. IR spectra were obtained as $\mathrm{KBr}$ pellets on a Perkin-Elmer FTIR 2000 spectrometer. Mass Spectra were measured on a Kratos AEI MS-50 instrument using electron impact (EI). Melting points were determined without further correction. Ethylene oligomerization results were recorded on a HP5890 Series II gas chromatograph (HewlettPackard).

Compound 2-hydroxy-5-tert-butylisophthaldehyde was prepared according to an established procedure. ${ }^{14}$ While MAO $\left(1.4 \mathrm{~mol} \mathrm{l}^{-1}\right)$ was purchased from Albemarle Corp (USA); Nickel or cobalt chloride and all of the anilines were used commercially without further purification unless stated otherwise.

\section{Preparation of ligands}

$\left(\mathbf{L}_{1}\right)$ : To a solution of 2-hydroxy-5-tert-butylisophthaldehyde $(0.62 \mathrm{~g}, 3 \mathrm{mmol})$ with a few drops of glacial acetic acid in anhydrous ethanol $15 \mathrm{~mL}$ under $\mathrm{N}_{2}$ at $50{ }^{\circ} \mathrm{C}$ was added a solution of 2,3-dimethylaniline $(0.73 \mathrm{~g}, 6 \mathrm{mmol})$ in anhydrous ethanol $(10 \mathrm{ml})$ over a period of 20 min with stirring. Then the mixture was refluxed for additional $2 \mathrm{~h}$. Upon cooling to room temperature, the volatiles were removed under vacuum, and the residue was recrystallized from ethanol giving the yellow crystals $0.87 \mathrm{~g}$ in $70 \%$ yield, mp. $131-133^{\circ} \mathrm{C}$. ${ }^{1} \mathrm{H}-\mathrm{NMR}\left(\mathrm{CDCl}_{3}\right), \delta$, ppm: $13.96(1 \mathrm{H}, \mathrm{s}), 8.79(2 \mathrm{H}, \mathrm{br}), 6.94-7.16(6 \mathrm{H}, \mathrm{m}), 2.34-2.36(12 \mathrm{H}$, m), 1.57 (6H, s), 1.42 (9H, s). IR(KBr), cm ${ }^{-1}: 3593$ (m), 2963 (s), 1622, 1574 (vs), 1465 (s), 1377, 1309, 1284, 1239, 1219, 1091, 1035, 1009 (s), 888, 782 (s). EI-MS (m/z): $412\left(\mathrm{M}^{+}\right.$, 3.5\%), 293 ( $\mathrm{M}^{+}$-NAr', 7.4\%), $292\left(\mathrm{M}^{+}-\mathrm{NAr}-\mathrm{H}, 43.7 \%\right), 291\left(\mathrm{M}^{+}-\mathrm{NAr} '-2 \mathrm{H}, 100 \%\right), 277$ (4.4\%), 132 (8.7\%), 120 (5.4\%), 105 (8.7\%). Anal. Calcd For $\mathrm{C}_{28} \mathrm{H}_{32} \mathrm{~N}_{2} \mathrm{O}: \mathrm{C}, 81.51 ; \mathrm{H}, 7.82$; $\mathrm{N} ; 6.79$. Found: C, 81.44; H, 7.81; N, 6.82\%.

$\left(\mathbf{L}_{2}\right)$ : By using the procedure described above for synthesis of $\mathrm{L}_{1}$, the ligand $\mathrm{L}_{2}$ was obtained by the reaction of 2-hydroxy-5-tert-butylisophthaldehyde with 2, 5-dimethylaniline as a red crystals $1.06 \mathrm{~g}$ in $85 \%$ yield, mp. $151-153^{\circ} \mathrm{C} .{ }^{1} \mathrm{H}-\mathrm{NMR}\left(\mathrm{CDCl}_{3}\right), \delta$, ppm: $14.06(1 \mathrm{H}, \mathrm{s}), 8.79$ (2H, br), 6.90-7.15 (6H, m), $2.38(12 \mathrm{H}, \mathrm{s}), 1.57(6 \mathrm{H}, \mathrm{s}), 1.42(9 \mathrm{H}, \mathrm{s}) . \mathrm{IR}(\mathrm{KBr}), \mathrm{cm}^{-1}: 3436$ (m), 2963 (s), 1617, 1570 (vs), 1465 (s), 1373, 1290, 1218, 1155, 1009 (s), 877, 765(s). 
EI-MS (m/z): $412\left(\mathrm{M}^{+}, 6.2 \%\right), 292\left(\mathrm{M}^{+}-\mathrm{NAr}-\mathrm{H}, 42.6 \%\right), 291\left(\mathrm{M}^{+}-\mathrm{NAr}{ }^{\prime}-2 \mathrm{H}, 100 \%\right), 277$ (4.3\%), 132 (6.5\%), 120 (6.3\%), 105 (7.7\%). Anal. Calcd For $\mathrm{C}_{28} \mathrm{H}_{32} \mathrm{~N}_{2} \mathrm{O}$ : C, 81.51; H, 7.82; $\mathrm{N} ; 6.79$. Found: C, 81.55; H, 7.84; N, 6.78\%.

$\left(\mathbf{L}_{3}\right)$ : By using the procedure described above for synthesis of $\mathrm{L}_{1}$, the ligand $\mathrm{L}_{3}$ was obtained by the reaction of 2-hydroxy-5-tert-butylisophthaldehyde with 3,5-dimethylaniline as a red powder $0.93 \mathrm{~g}$ in $75 \%$ yield. mp. $61-62^{\circ} \mathrm{C} .{ }^{1} \mathrm{H}-\mathrm{NMR}\left(\mathrm{CDCl}_{3}\right), \delta$, ppm: $14.04(1 \mathrm{H}, \mathrm{s}), 8.86$ $(2 \mathrm{H}, \mathrm{br}), 6.94(6 \mathrm{H}, \mathrm{s}), 2.38(12 \mathrm{H}, \mathrm{s}), 1.57(6 \mathrm{H}, \mathrm{s}), 1.41(9 \mathrm{H}, \mathrm{s}) . \mathrm{IR}(\mathrm{KBr}), \mathrm{cm}^{-1}: 3486(\mathrm{~m})$, 2959 (s), 1622, 1579 (vs), 1465 (s), 1359, 1264, 1222, 1150, 1006 (s), 849, 765 (s). EI-MS $(\mathrm{m} / \mathrm{z}): 412\left(\mathrm{M}^{+}, 100 \%\right), 411\left(\mathrm{M}^{+}-\mathrm{H}, 12.8 \%\right), 292\left(\mathrm{M}^{+}-\mathrm{NAr}{ }^{\prime}-\mathrm{H}, 52.2 \%\right), 291\left(\mathrm{M}^{+}-\mathrm{NAr}{ }^{\prime}-2 \mathrm{H}\right.$, 18.0\%), 277 (5.2\%), 132 (9.6\%), 120 (3.6\%), 105 (22.6\%). Anal. Calcd For $\mathrm{C}_{28} \mathrm{H}_{32} \mathrm{~N}_{2} \mathrm{O}: \mathrm{C}$, $81.51 ; \mathrm{H}, 7.82 ; \mathrm{N} ; 6.79$. Found: C, 81.52; H, 7.83; N, 6.76\%.

\section{Preparation of complexes}

Complex (1): $\mathrm{CoCl}_{2} \cdot 6 \mathrm{H}_{2} \mathrm{O}(1 \mathrm{mmol})$ and $\mathrm{L}_{1}(1 \mathrm{mmol})$ were combined in a Schlenk flask under an $\mathrm{N}_{2}$ atmosphere. EtOH $(10 \mathrm{~mL})$ was added, and the mixture was stirred at room temperature for 10 hours. The crude product was filtrated, washing with diethyl ether and the product was recrrystallized from ethanol afford complex 1 as a green powder $0.46 \mathrm{~g}$ in 85\% yield. IR(KBr), cm ${ }^{-1}: 3417$ (m), 2961 (m), 1636 (vs), 1596 (s), 1537 (s), 1467 (m), $1363,1325,1292,1232,1071$ (s). Anal. Calcd For $\mathrm{C}_{28} \mathrm{H}_{32} \mathrm{~N}_{2} \mathrm{O} \cdot \mathrm{CoCl}_{2} \cdot \mathrm{H}_{2} \mathrm{O}: \mathrm{C}, 60.12 ; \mathrm{H}$, 5.95; N, 5.01. Found: C, 59.89; H, 6.11; N, 4.97\%.

Complex (2): Using the procedure described above, the reaction of $\mathrm{L}_{2}$ and $\mathrm{CoCl}_{2} \cdot 6 \mathrm{H}_{2} \mathrm{O}$ gave complex $20.42 \mathrm{~g}$ in $78 \%$ yield as a green powder. $\mathrm{IR}(\mathrm{KBr}), \mathrm{cm}^{-1}: 3438(\mathrm{~m}), 2961(\mathrm{~m}), 1641$ (s), 1616 (s), 1538 (s), 1461 (m), 1362, 1325, 1282(w), 1238, 1060 (s). Anal. Calcd For $\mathrm{C}_{28} \mathrm{H}_{32} \mathrm{~N}_{2} \mathrm{O} \cdot \mathrm{CoCl}_{2}$ : C, 62.00; H, 5.95; N, 5.16. Found: C, 61.89; H, 5.92; N, 5.17\%.

Complex (3): Using the procedure described above, the reaction of $\mathrm{L}_{2}$ and $\mathrm{CoCl}_{2} \cdot 6 \mathrm{H}_{2} \mathrm{O}$ gave complex $30.44 \mathrm{~g}$ in $81 \%$ yield as a green powder. $\mathrm{IR}(\mathrm{KBr}), \mathrm{cm}^{-1}: 3435(\mathrm{~m}), 2960(\mathrm{~m}), 1638$ (s), 1591(s), 1539 (m), 1479 (m), 1239, 1201, 1145 (m), 1078, 1028 (s). Anal. Calcd For $\mathrm{C}_{28} \mathrm{H}_{32} \mathrm{~N}_{2} \mathrm{O} \cdot \mathrm{CoCl}_{2}$ : C, 62.00; H, 5.95; N, 5.16. Found: C, 61.87; H, 5.87; N, 5.19\%.

Complex (4): Using the procedure described above, the reaction of $\mathrm{L}_{1}$ and $\mathrm{NiCl}_{2} \cdot 6 \mathrm{H}_{2} \mathrm{O}$ gave complex $40.41 \mathrm{~g}$ in $75 \%$ yield as a brown powder. $\mathrm{IR}(\mathrm{KBr}), \mathrm{cm}^{-1}: 3382(\mathrm{~m}), 2961(\mathrm{~m}), 1647$ (s), 1577 (s), 1537 (m), 1466 (m), 1404, 1357, 1327, 1289, 1233, 1164 (m), 1046 (s). Anal. Calcd For $\mathrm{C}_{28} \mathrm{H}_{32} \mathrm{~N}_{2} \mathrm{O} \cdot \mathrm{NiCl}_{2}$ : C, 62.03; H, 5.95; N, 5.17. Found: C, 62.08; H, 5.93; N, $5.29 \%$.

Complex (5): Using the procedure described above, the reaction of $\mathrm{L}_{2}$ and $\mathrm{NiCl}_{2} \cdot 6 \mathrm{H}_{2} \mathrm{O}$ gave complex $50.42 \mathrm{~g}$ in $78 \%$ yield as a brown powder. IR(KBr), $\mathrm{cm}^{-1}: 3370(\mathrm{~m}), 2959(\mathrm{~m})$, 1649 (s), 1539 (s), 1454 (s), 1410, 1354, 1326, 1292 (w), 1238, 1118 (s). Anal. Calcd For $\mathrm{C}_{28} \mathrm{H}_{32} \mathrm{~N}_{2} \mathrm{O} \cdot \mathrm{NiCl}_{2} \cdot \mathrm{H}_{2} \mathrm{O}: \mathrm{C}, 60.03 ; \mathrm{H}, 6.12 ; \mathrm{N}, 5.00$. Found: $\mathrm{C}, 60.13 ; \mathrm{H}, 6.10 ; \mathrm{N}, 4.97 \%$.

Complex (6): Using the procedure described above, the reaction of $\mathrm{L}_{3}$ and $\mathrm{NiCl}_{2} \cdot 6 \mathrm{H}_{2} \mathrm{O}$ gave complex $60.42 \mathrm{~g}$ in $78 \%$ yield as a brown powder. IR( $\mathrm{KBr}), \mathrm{cm}^{-1}: 3380(\mathrm{br}), 2960$ (m), 1638 (s), 1536 (s), 1364, 1330, 1292(w), 1239, 1200 (m), 1143 (w), 1064, 1024 (s), 853 (s). Anal. Calcd For $\mathrm{C}_{28} \mathrm{H}_{32} \mathrm{~N}_{2} \mathrm{ONiCl}_{2}$ : C, 62.03; H, 5.95; N, 5.17. Found: C, 62.13; $\mathrm{H}, 5.70 ; \mathrm{N}, 5.31 \%$. 


\section{General procedure for ethylene oligomerization}

A flame dried three-neck round flask was vacuated-filled three times by nitrogen. Then ethylene was charged with $30 \mathrm{ml}$ of freshly distilled toluene and stirred. At the room temperature, the aluminum cocatalyst MAO was added via syringe. The solution was stirred and the precatalyst complex ( $1-6,5 \mu \mathrm{mol}$ in $5 \mathrm{ml}$ toluene) was added to the reaction mixture via syringe. After stirred under 1 atm ethylene pressure for $20 \mathrm{~min}$, the oligomerization was terminated by acidified ethanol. An aliquot of the reaction mixture was analyzed using gas chromatrography. Their activity and distribution of the oligomers were collected in Table 1.

Table 1. Activity and Distribution of the Oligomerization ${ }^{\mathrm{a}}$

\begin{tabular}{lllll}
\hline \multirow{2}{*}{ Complex } & \multirow{2}{*}{$\mathrm{Al} / \mathrm{Ni}$} & $\begin{array}{l}\text { Activity } \\
(\mathrm{g} / \mathrm{mol} \cdot \mathrm{h} \cdot \mathrm{atm})\end{array}$ & \multicolumn{2}{c}{ Distribution of oligomers (\%) } \\
\cline { 4 - 5 } & & $\mathrm{C}_{4}$ & $\mathrm{C}_{6}$ \\
\hline 1 & 500 & $3.65 \times 10^{3}$ & 72.22 & 27.28 \\
2 & 500 & $2.38 \times 10^{3}$ & 74.71 & 25.29 \\
3 & 500 & $1.78 \times 10^{3}$ & 73.80 & 26.20 \\
4 & 500 & $4.57 \times 10^{4}$ & 69.27 & 30.73 \\
5 & 500 & $2.82 \times 10^{4}$ & 67.33 & 32.67 \\
6 & 500 & $1.98 \times 10^{4}$ & 65.97 & 34.03 \\
\hline \multicolumn{3}{c}{ a Condition: Toluene solvent, 1atm of ethylene, $\mathrm{T}=15^{\circ} \mathrm{C}}$.
\end{tabular}

\section{Results and Discussion}

Synthesis and characterization

2,6-bis(imino)phenoxy ligands $\mathrm{L}_{1}-\mathrm{L}_{3}$ were prepared in good yields by condensation of one equivalent of the appropriate aniline with one equivalent of 2-hydroxy-5-tertbutylisophthaldehyde (Scheme 1). Compounds $\mathrm{L}_{1}-\mathrm{L}_{3}$ were characterized by microanalysis, ${ }^{1} \mathrm{H}-\mathrm{NMR}$ and mass spectrometry. The complexes $1-6$ were synthesized by dissolving nickel chloride or cobalt chloride in ethanol (Scheme 1), followed by addition of one equivalent of ligand. The complexes precipitated from the reaction solution. After recrystallized from ethanol, the complexes were obtained in good yields and high purity. All the complexes were confirmed with elemental analysis and IR spectroscopy. The elemental analysis results revealed that the components of all complexes were in accord with the formula $\mathrm{MLX}_{2}$.

\section{Oligomerization of ethylene}

Upon treatment with methylaluminoxane (MAO), all of the complexes are active ethylene oligomerization catalysts. Table 1 lists their activity and molecular weight distribution of the oligomers. The nature of the metal center has a major influence on catalytic activities. In general, $\mathrm{Ni}$ (II) catalysts are more active than their corresponding $\mathrm{Co}(\mathrm{II})$ analogues under the same condition. The most active $\mathrm{Ni}(\mathrm{II})$ catalyst is complex $1\left(4.57 \times 10^{4} \mathrm{~g}\right.$ (ethylene) $\mathrm{mol}^{-1}$ $\left.(\mathrm{Ni}) \mathrm{h}^{-1}\right)$, While the $\mathrm{Co}(\mathrm{II})$ complexes are about $10^{3} \mathrm{~g}($ ethylene $) \mathrm{mol}^{-1}(\mathrm{Co}) \mathrm{h}^{-1}$ for oligomerization. Complexes $1-3(4-6)$ revealed that a reduction of steric methyl at the ortho-aryl position resulted in the decrease of their activities, and electronic environmental around the central metal affected the catalytic activities. In the same condition, catalysts 1 (4) are more active than the catalysts 3 (6). Without methyl group in the aryl rings and 3 (6) displays an activity of $1.78 \times 10^{3}\left(1.98 \times 10^{4}\right) \mathrm{g}($ ethylene $) \mathrm{mol}^{-1}(\mathrm{M}) \mathrm{h}^{-1}$, approximately complex 1 (4) with one methyl at the ortho-aryl with an activity of $3.65 \times 10^{3}\left(4.57 \times 10^{4}\right)$ $\mathrm{g}($ ethylene $) \mathrm{mol}^{-1}(\mathrm{M}) \mathrm{h}^{-1}$. The same phenomenon was observed in previously research. ${ }^{12-13}$ The oligomers are from $\mathrm{C}_{4}$ to $\mathrm{C}_{6}$. The substituents of the complexes affect distribution of the 
oligomers to some extent. Comparing with the 2,6-bis(imino)pyridyl ligands ${ }^{6-8}$, when we change the central pyridyl moiety to phenol, their complexes only show oligomerization activity, no polymerization activity; at the same time, the selectivity in ethylene conversion are not very well.

\section{Conclusions}

We have synthesized six cobalt and nickel complexes. Upon treatment with methylaluminoxane, they are all active ethylene oligomerization catalysts. The oligomers are from $\mathrm{C}_{4}$ to $\mathrm{C}_{6}$.

\section{Acknowledgements}

We thank the financial support from Hebei University.

\section{References}

1. Ittle S D, Johnson L K and Brookhart M Chem. Rev., 2000, 100, 1169.

2. Britovsek G J P, Gibson V C and Wass D F, Angew. Chem. Int. Ed. 1999, 38, 428.

3. Johnson L K, Mecking S and Brookhart M J. Am. Chem. Soc, 1996, 118, 267.

4. Killian C M, Tempel D J and Johnson L K J. Am. Chem. Soc, 1996, 118, 11664.

5. Johnson L K, Killian C M and Brookhart M J. Am. Chem. Soc, 1995, 117, 6414.

6. Mecking S, Johnaon L K, Wang L, Brookhart M J. Am. Chem. Soc, 1998, 120, 888.

7. Small B L, Brookhart M and Bennett A M A, J. Am. Chem. Soc, 1998, 120, 4049.

8. Britovsek G J P, Gibson V C and Kimberley B S, Chem. Commun., 1998, 849.

9. Wang C, Friedrich S and Younkin T R Organometallics, 1998, 17, 3149.

10. Small B L and Brookhart M, J. Am. Chem. Soc, 1998, 120, 7143.

11. Wang LY, Sun W-H and Han L Q, J. Organomet. Chem. 2002, 650, 59.

12. Du J L, Han L Q, Cui Y, Li J T, Li Y and Sun W-H Aust. J. Chem., 2003, 56, 703.

13. Du J L, Li L-J and Li Y F Inorg. Chem. Commun., 2005, 8, 246.

14. Drago R S, Desmond M J, Corden B B and Miller K A J. Am. Chem. Soc., 1983, 105, 2287. 


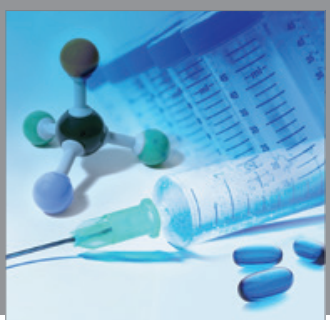

International Journal of

Medicinal Chemistry

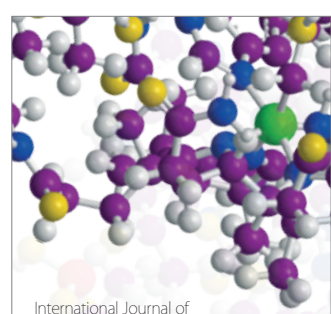

Carbohydrate Chemistry

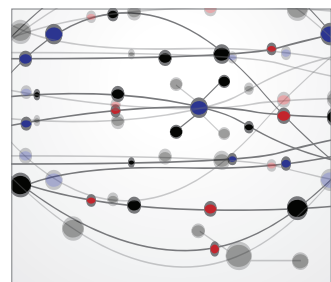

The Scientific World Journal
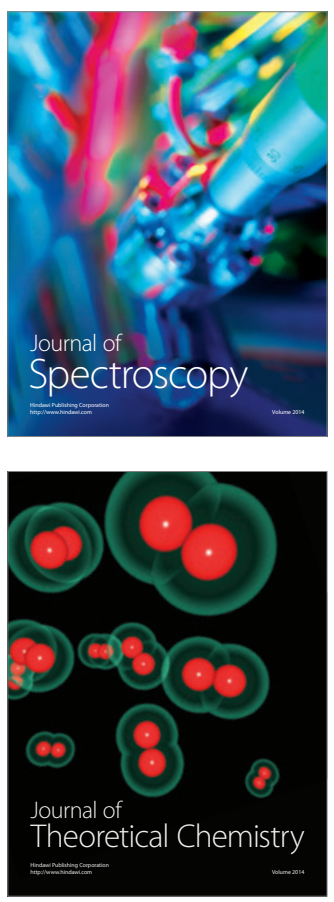
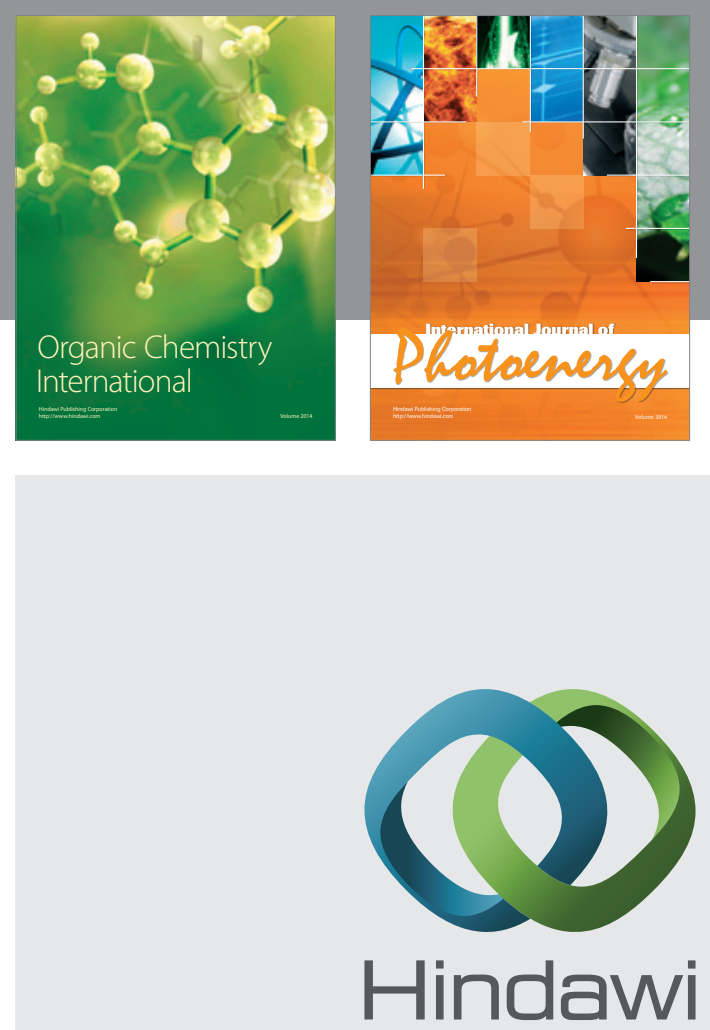

Submit your manuscripts at

http://www.hindawi.com
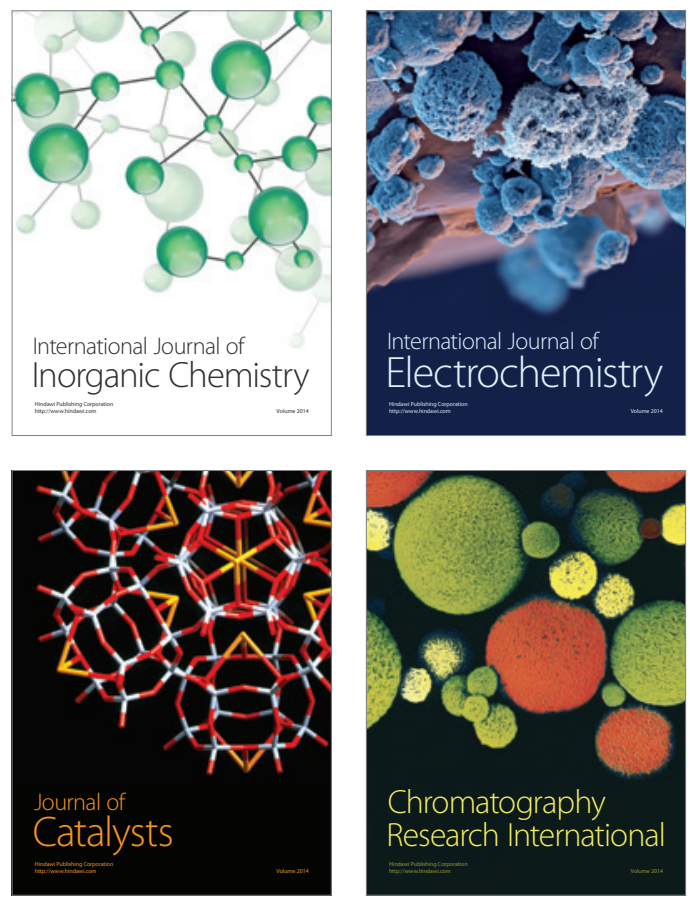
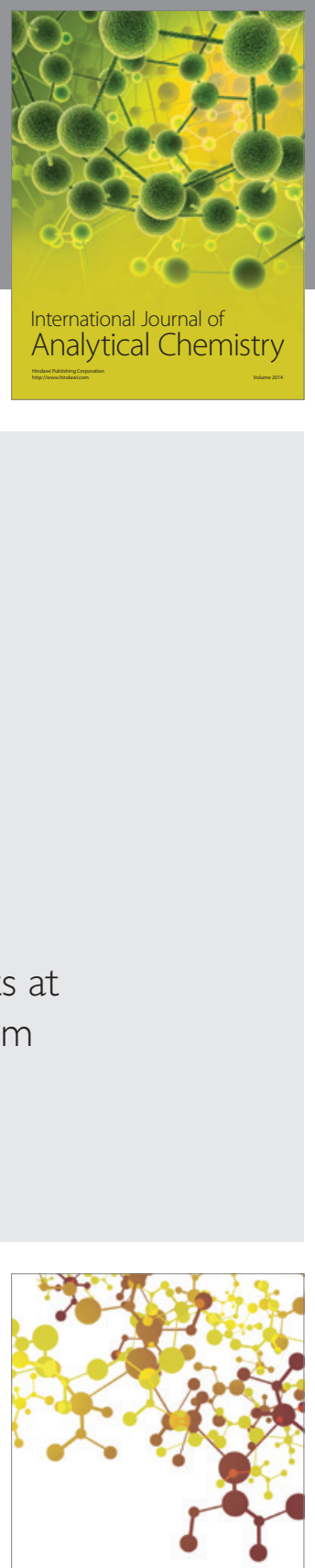

Journal of

Applied Chemistry
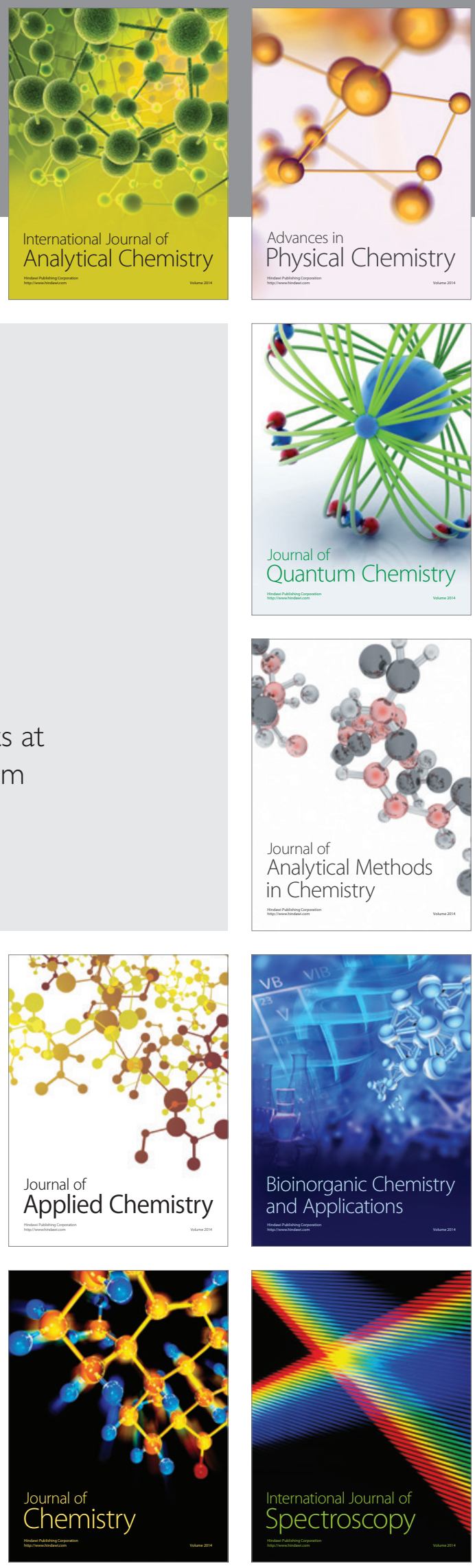